\title{
Cyberbehavior: A Bibliometric Analysis
}

\author{
Manuel J. Serafin ${ }^{1}$, Gustavo R. García-Vargas², \\ María del Pilar García-Chitiva ${ }^{3}$, Mario I. Caicedo ${ }^{4}$, Juan C. Correa $^{*}$ \\ ${ }^{1}$ Departamento de Ciencias Básicas, Vicerrectorado "Luis Caballero Mejías", \\ Universidad Nacional Experimental Politécnica "Antonio José de Sucre", Venezuela. \\ ${ }^{2}$ Facultad de Psicología, Fundación Universitaria Konrad Lorenz, Bogotá, Colombia \\ ${ }^{3}$ Centro de Estudios Aeronáuticos, Aeronaútica Civil, Bogotá, Colombia \\ ${ }^{4}$ Departamento de Física, Universidad Simón Bolívar, Caracas, Venezuela
}

\begin{abstract}
Cyberbehavior, as the object of study of cyberpsychology, refers to the set of human behaviors that require an electronic device with Internet access to interact with other persons in both synchronous and asynchronous way. Although the first studies of cyberbehavior took place with the popularization of the so-called "Social Web", few works focus on reviewing this literature. This paper aims to provide a bibliometric review of the scientific publication on cyberbehavior by analyzing all the documents published by four of the most representative international journals on the topic. The results show that in spite of the growth of the scientific community, the research has focused on the use of Facebook and other social media, while relevant subject matters for psychologists (e.g., motivation, personality, Internet addiction, cyberbullying or self-expression) remain little explored.
\end{abstract}

Keywords: bibliometrix; cyberpsychology; scientific collaboration.

\section{Introduction}

Scientific and technological advances have always been crucial factors in producing important changes in the whole history of the human race [17. The magnitude of these changes and the rate at which they occur are increasing, and they have become part of us to the point of making life impossible as we understand it in the absence of technology 15.

Since the worldwide popularization of the Internet, we can differentiate two manifestations of human behavior. The first one, known as real behavior, occurs in "natural" environments such as the office, the classroom, and the home in the usual sense. The second one, known as cyberbehavior, takes place in virtual environments that require the use of electronic devices to access the web to interact with other people or objects, in both synchronous (with continuous interactions without interruptions) and an asynchronous way (with intermittent communications, depending on the individual's availability to interact) [35. Based on this definition, what do we know, then, about cyberbehavior? Cyberbehavior is the

*Corresponding author: (Juan C. Correa) E-mail: juanc.correan@konradlorenz.edu.co 
object of study of a discipline called cyberpsychology 26. Roughly speaking, cyberpsychology focuses on studying the effects of the Internet and cyberspace on the individual and groups 31. According to Harley, Morgan and Frith 15. cyberpsychology refers to the "study of how new communication technologies influence, and are influenced by, human behaviours and subjectivities" (p. vii).

The interest in cyberbehavior was already noted several decades ago by notable science fiction writers such as Robert A. Heinlein, Isaac Asimov or Arthur C. Clark, and nowadays its relevance is evident not only in the production of popular films and television series (e.g., "Black Mirror" or "The Social Network"), but in the creation of specialized scientific journals such as "Cyberpsychology, Behavior and Social Networking", "Cyberpsychology and Behavior", "Computers in Human Behavior" and "Human Computer Interaction".

Cyberbehavior began to be known back in 2000 when Tim O'Reilly 28 popularized the term "Web 2.0" or "Social Web" [47, which refers to those websites that allow its users to interact and collaborate, being generators of content within a virtual community. Some examples of Web 2.0 are web communities, services, and Web applications, social networking, and video hosting services, wikis and blogs, mashups and folksonomies. Cyberbehavior is conspicuous, as it is present when talking about subjects such as cyber-bullying [57, perceived privacy on Snapchat [35], Facebook security for teenagers [51, the paradox of happiness in social networks 3 , the propagation of false news in social networks [22, the publication on Twitter of conspiracy theories about viruses or diseases [54, the consumption of pornography on the Internet 25], the laundering of money with bitcoins by criminal organizations [52] or the use of services to order food over the Internet $[\underline{6}$.

The diversity of topics associated with cyberbehavior and their implications for other areas of knowledge makes their interest naturally multidisciplinary. Until 2009, conceptions of cyberbehavior from psychological perspectives were in an early phase 31. Up to the best of our knowledge, there exist two types of reviews focusing on topics related to cyberbehavior. The first one, known as "CyberEurope", targets the research of cyberpsychology in Europe between 2006 and 2016 [36, 37, 38, 39, 40, 41, 42, 43, 44, 45, 46. "CyberSightings" is a second type of review that covers scientific breakthroughs, latest devices, conferences, book reviews, and general announcements of interest to researchers and clinicians 19, 10, 11, 12, 13, 14. Apart from these efforts, we are not aware of bibliometric reviews of cyberbehavior at a worldwide scale. Because of its multidisciplinary relevance, we believe that the conceptions of cyberbehavior will reach maturity when psychological approaches integrate with proposals from physics, computing, economics, linguistics, communication, and marketing, due to to the methodological contributions that these disciplines might offer about getting access to the data of the cyberbehavior and how to analyze them.

A couple of cases will illustrate why other disciplines can provide valuable methodological contributions [8]. For example, a clear contribution from computer sciences refers to the use of web scraping as a technique that allows researchers the possibility to obtain public data from the Internet 21. The employment of web scraping, for example, is useful to understand the influence of Twitter on electoral processes [5] or evaluating the impact of traffic conditions on key performance indicators of online food delivery platforms [ 6 . The intersection between network science [2] and economic sciences provides another clear contribution to analyzing the financial transactions carried out in cryp- 
tocurrencies and understand why the blockchain system can be inefficient when it comes to registering quickly and accurately the economic exchanges between buyers and sellers 29 .

The ideas mentioned above should make clear why cyberbehavior is relevant nowadays. Although it is not possible to exhaustively enumerate all the interdisciplinary links that exist to study cyberbehavior, we can, however, analyze a representative sample of these studies. This work aims to provide a bibliometric review of the articles published in four international journals with the highest impact factor within the scientific community specialized in the area. Supplementary materials accompany the approach presented in this work (e.g., raw data, and computational scripts developed in $\mathrm{R}$ ). These materials (see subsection 2.3 allow other readers to verify and reproduce the results we show after the following section. In section 3, we describe the most relevant findings of the scientific publication on cyberbehavior. The work ends with a discussion in section 4 where we argue about the future of research on this subject.

\section{Methodology}

\section{$2.1 \quad$ Research design}

This work follows the specifications of a bibliometric study [48. Bibliometric studies, according to Aria \& Cuccurullo [1], are particularly useful to complement the literature review of a topic, by structuring and quantifying bibliographic information with the purpose of identifying the elements that make up the scientific study of a subject matter; for example, the most outstanding and influential authors and institutions in the scientific community, the most frequent keywords, the changes in the thematic limits of the disciplines and the identification of temporary research trends, among other aspects.

\subsection{Data Collection Procedure}

On November 15, 2018, we used the SCOPUS database to retrieve the bibliographic information of all the documents published by four of the most representative international journals on cyberbehavior: "Cyberpsychology, Behavior and Social Networking" (ISSN: 21522723), "Cyberpsychology and Behavior" (ISSN: 10949313), "Computers in Human Behavior" (ISSN: 07475632) and "Human-Computer Interaction" (ISSN: 07370024). To consult the bibliographic information in SCOPUS, we used the "International Standard Serial Number" or ISSN of each journal as our search criteria, with the following query string (ISSN (21522723) OR ISSN (10949313) OR ISSN (07475632) OR ISSN (07370024)). We downloaded in bibtex format the resulting bibliographic records year by year, and we processed them in the $\mathrm{R}$ environment [33] with the help of the bibliometrix package [1]. In total, we were able to retrieve 6934 records published between 1985 and 2018. Since cyberbehavior began to occur thanks to the worldwide popularization of Web 2.0 28], we decided to analyze the records published between 2000 and 2018 $(\mathrm{n}=6761)$. In the following web address (https://github.com/jcorrean/ Cyberpsychology-A-Bibliometric-Analysis) the interested reader can access both the data of this work and its procedure for reproducing our results. 


\subsection{Data Analysis}

We used descriptive statistics and data visualization techniques in $\mathrm{R}[53$. We calculated the average annual growth rate of the publications with the algorithm "Annual growthrate" implemented in the "bibliometrix" package of Aria \& Cuccurullo 1. Furthermore, we used network analysis and visualization techniques 19 to analyze the evolution of the network that depicts the collaboration between authors with the new graphical user interface called "biblioshiny" launched from bibliometrix version 2.0.2. This type of analysis allows to visually understand the growth of a particular scientific community. In addition, we identified the most dominant topics with the algorithm "KeywordGrowth" of the bibliometrix package. We employed standard text mining techniques to identify thematic clusters inside each journal. We discarded the bibliographic records that corresponded to the notes of CyberEurope and Cybersighting to get a resulting corpus consisting of 6678 unique article titles without commonuse jargon and English stopwords like articles, prepositions or adverbs whose frequency of appearance makes them less informative from a semantic point of view. We used the words of each title to generate a term-document matrix as the raw input that allowed us to build a dissimilarity matrix that we later employed to estimate pairwise-distances between articles, and extract the words that belong to each cluster from each journal.

\section{Results}

Figure 1A shows the top-ten of most productive countries in the publication of scientific articles on cyberbehavior. The United States of America, Taiwan, South Korea, the United Kingdom, and Germany occupied the first five positions in this list, while the Netherlands, Italy, Canada, Spain, and China complemented this top-ten. Figure $1 \mathrm{~B}$ shows that the publication of articles between 2000 and 2018 presents two distinct periods, according to their volume of production. The first period, between 2000 and 2009, was characterized by a publication that did not exceed 150 articles per year. As of 2010, the publication of articles changed dramatically, increasing its volume by almost two orders of magnitude.

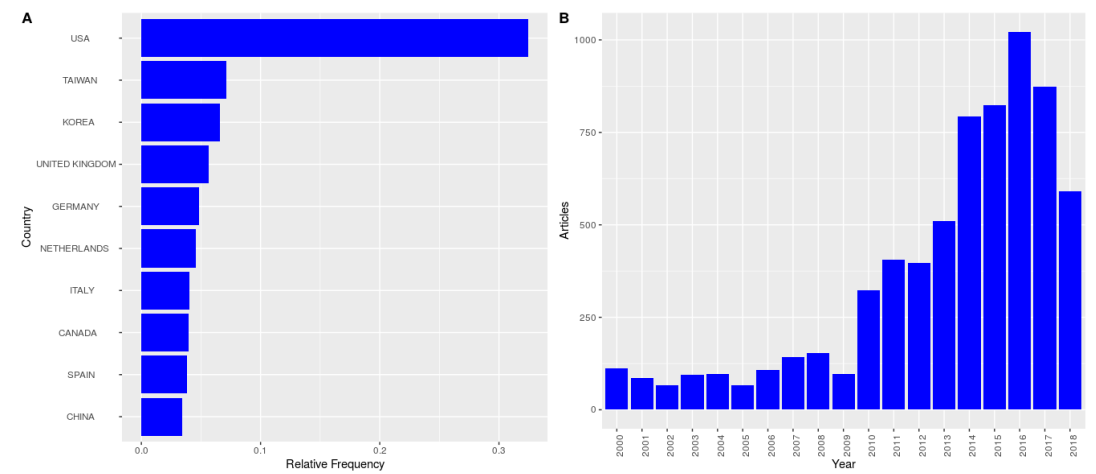

Figure 1: (A) Top-ten of most productive countries. (B) Publication volume between 2000-2018 
The interannual average growth for the whole series was $9.68 \%$. On average, any paper published in the journals that we queried is usually cited 23.79 times. In 2000, the size of the scientific community was composed of 227 researchers, distributed across 17 countries, and by the end of 2018, its size reached a total of 13,059 researchers, spread across 3,893 institutions in 82 countries. Figure 2 depicts the evolution of scientific collaboration in the last 19 years where countries with the darkest blue proved to be the most active ones in publishing, and curved pink lines reflect the collaboration between countries.

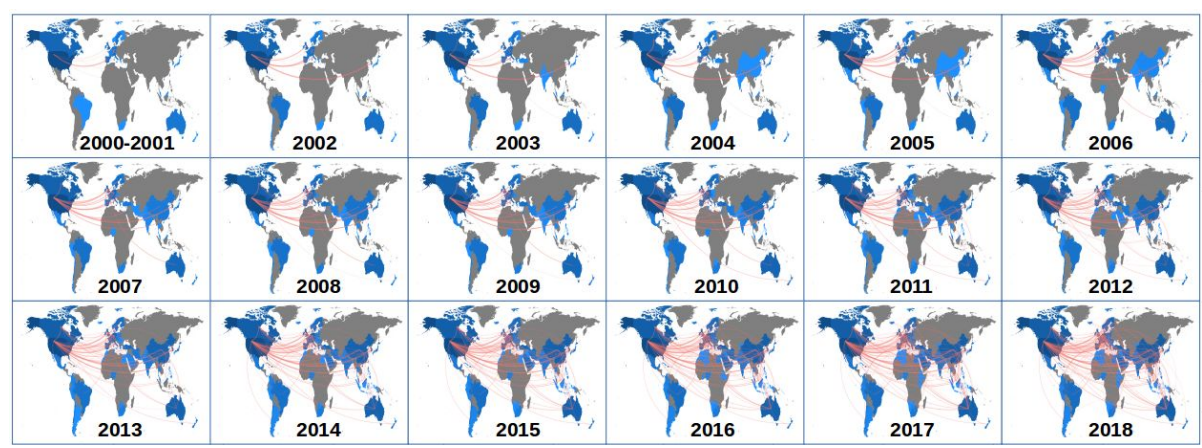

Figure 2: Evolution of the scientific collaboration network between 2000 and 2018

The average number of authors per document was 1.93, while the average number of documents per author was 0.518 . The index of collaboration among authors was 2.18 with $89.70 \%$ of articles signed by two or more authors. Figure 3 shows the network of the most productive authors in the publication of topics on cyberbehavior (those that occupy the 99 th percentile in number of publications within the whole series).

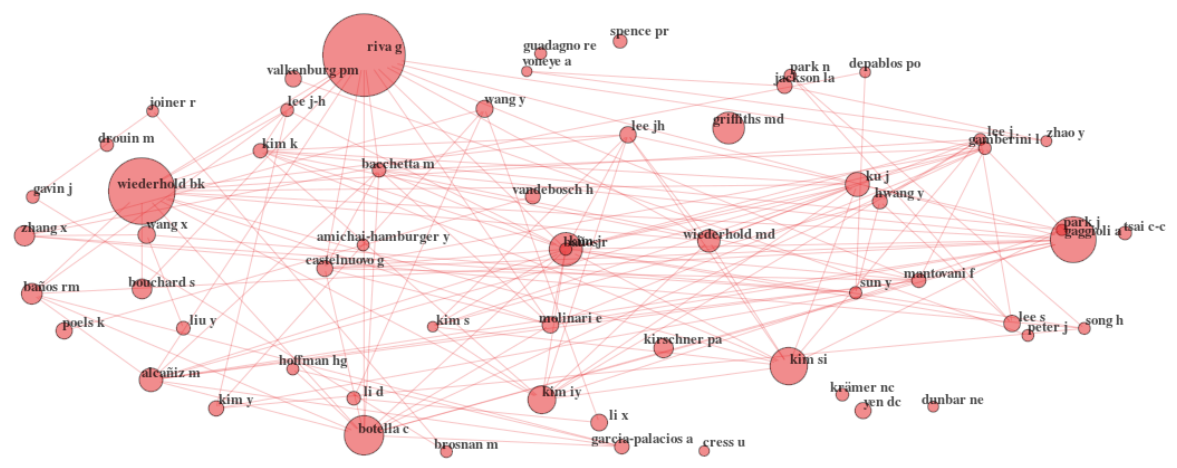

Figure 3: Most productive authors collaboration network

In this network, authors are red nodes or points whose size represents the number of papers they have published between 2000 and 2018. The leaders of the most productive authors are editors in chief or regular editors of notes and reviews of the cyberbehavior community. The connection between authors is visualized by a straight line that connects two or more researchers if they 
are authors or co-authors of the same work. The transitivity coefficient of the authors network was 0.527 . This number represents the expected value of the probability that two authors will write a new work if they both share a co-author within this same network. The network that involves the 13,059 authors has a diameter of 31 nodes. This diameter represents the number of articles that a reader should read to grasp the panorama of topics that constitute the study of cyberbehavior by the journals consulted.

The dominant subject matters in cyberbehavior were those terms with the highest frequency of appearance within the authors-assigned keywords of each article. Figure 4 summarizes the growth in the number of publications that contain the 20 most dominant authors-assigned keywords between 2010 and 2018 .

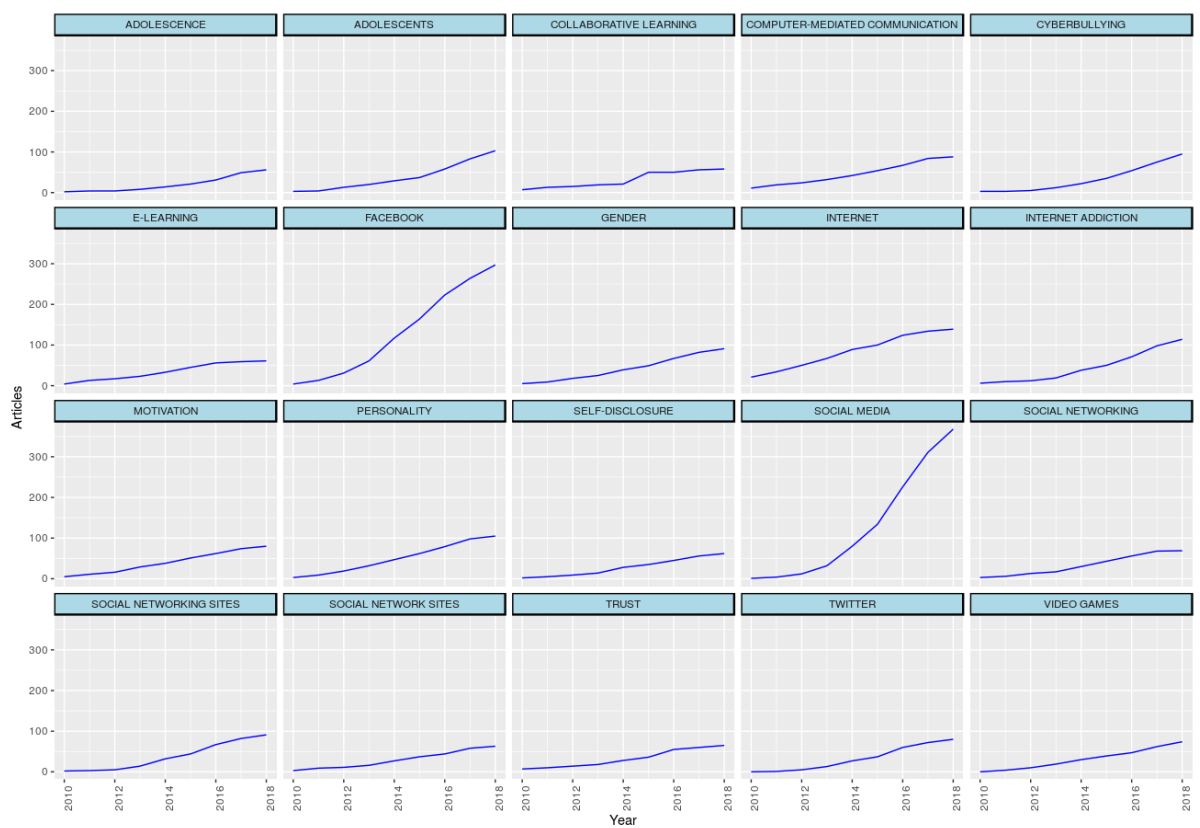

Figure 4: Top-20 rank of the most dominant authors-assigned keywords in the sample of published papers

In the last nine years, two terms occupied the first two positions in the top20 rank of most common authors-assigned keywords of published papers. These terms, "social networks" and "Facebook", highlight from all others by showing a steeper slope in Figure 4 . Interestingly, some of the concepts with greater relevance for psychologists such as "motivation", "personality", "self-expression", "Internet addiction", "gender", "adolescence", "cyberbullying" and "confidence" were not as visible (less pronounced slope) as "social networks" and "Facebook". It is also evident that the publication on cyberbehavior also shows some works on entertainment (i.e., video-games) and computer-mediated communication and learning (e.g., E-learning, collaborative learning). Although these less dominant yet visible keywords are more of the interest of software engineers and educators, respectively, they were not as prominent as the first two keywords of this rank. Moreover, keywords that reveal possible interdisciplinary links to 
tackle different aspects of cyberbehavior (e.g., telemedicine, cybersecurity, web scraping, application-program-interface, data science, network science, bitcoin, blockchain, virtual reality, cybersex) are missing from this rank.

Figure 5 depicts the thematic clusters that emerged from text mining the titles of the sampled articles. The largest cluster $(\mathrm{n}=2845)$ emerged from the papers published in Computers in Human Behavior with the following words in their titles: "virtual", "impact", "networks", "communication", "interaction", "new", "digital", "product", "reality", and "web". The second largest cluster $(\mathrm{n}=692)$ emerged from the papers published in Cyberpsychology, Behavior and Social Networking with the following words in their titles: "impact", "behavior", "perceived", "life", "digital", "training", "effects", "cyberbullying", "sexual", "theory". The third cluster $(\mathrm{n}=425)$ emerged from Cyberpsychology and Behavior with these words in their titles: "social", "communication", "web", "cyberspace", "effects", "effect", "women", "theory", "chat", "characteristics". The fourth $(\mathrm{n}=387)$ and fifth $(\mathrm{n}=338)$ clusters belonged to Computers in Human Behavior with these terms: "learning", "collaborative", "environments", "group", "multimedia", "cognitive", "reading", "effect", "system", "solving", "Internet", "adolescents", "cyberbullying", "addiction", "gender", "gaming", "use", "problematic", and "scale".
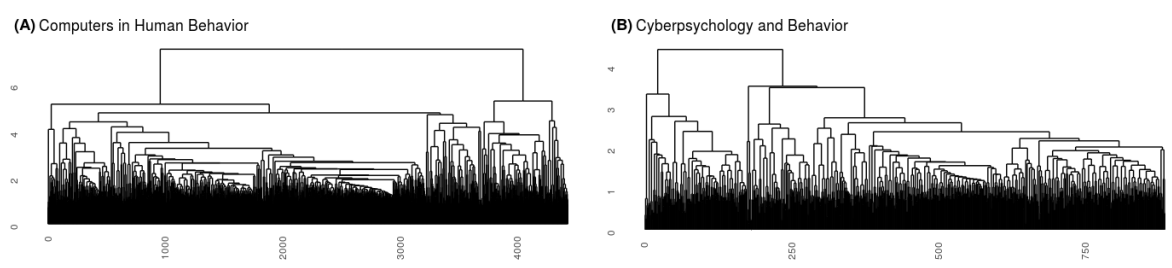

(C) Cyberpsychology, Behavior, and Social Networking
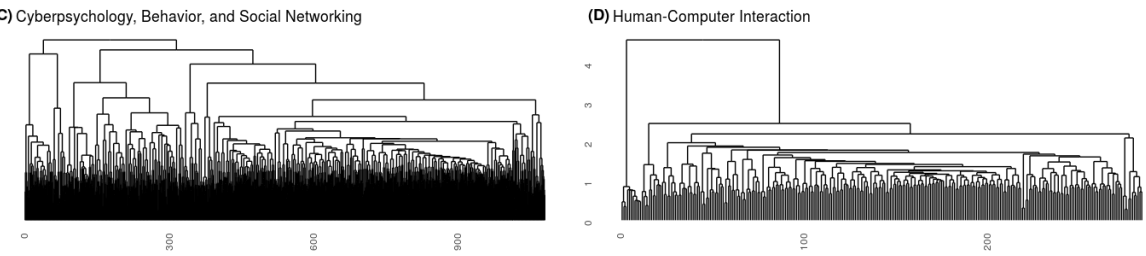

Figure 5: Thematic clusters from the titles of the articles published (A) Computers in Human Behavior, (B) Cyberpsychology and Behavior, Cyberpsychology, Behavior, and Social Networking, (D) Human-Computer Interaction

Some of the most cited papers that belonged to these clusters were those that analyzed why people use social networks [24, reviewed the research on cyberbullying [50, analyzed the intersection of users' personality and social media use [7, examined Facebook Groups users' gratifications [30, 34, described the motivations for play in online games [55, summarized virtual reality applications in the field of motor rehabilitation [16, synthesized the factors that facilitates remote work among working teams [27, or analyzed the use of Internet for cognitive therapies [56, online payment [18, generate trust on mobile commerce [23] and reviewed the role of social media in higher education [49]. 


\section{Discussion}

A bibliometric analysis of the scientific publication on cyberbehavior was the aim of this paper. We analyzed the bibliographic information of the articles published in four of the most influential journals in the area: Cyberpsychology, Behavior and Social Networking, Cyberpsychology and Behavior, Computers in Human Behavior, and Human-Computer Interaction. These analyses lead us to claim the following couple of contributions to the discipline.

While in previous studies explicit definitions of cyberbehavior are provided from the point of view of evolutionary psychology 31 or from subjective experiences that include the way in which people engage with Internet-based technologies [15, we showed another approach to cyberbehavior. In particular, we have illustrated the advantages of computational bibliometric reviews [1] implemented under the $\mathrm{R}$ environment [33], to facilitate other readers the reproduction of our results and verify the evidence we have provided 4. The possibility of using computational bibliometric reviews as a mean to generate new literature reviews or complement existing ones, is a fruitful way to understand the behavior of scientific communities, as well as the dominant topics in the research agendas of scientific groups. The adoption of our approach might be beneficial for $\mathrm{PhD}$ candidates and other early-career researchers 32 .

A second contribution of our work relates to our results. In spite of the growth of the scientific community, we have shown that the research has focused on the use of Facebook and other social media, while relevant subject matters for psychologists (e.g., motivation, personality, Internet addiction, cyberbullying or self-expression) are far from deeply explored. Arguably, the attention that Facebook has generated on the scientific community might be associated with its role as a profitable business model that posits significant ethical concerns regarding users privacy [20]. However, as cyberbehavior research also relates to other topics such as telemedicine, virtual reality, cybersex, E-commerce, and distance education, we foresee that future research on these topics will catch the attention of researchers coming from the realm of other disciplines distinct from psychology.

\section{References}

[1] Aria, M., Cuccurullo, C.: bibliometrix: An R-tool for comprehensive science mapping analysis. Journal of Informetrics 11(4), 959-975 (2017)

[2] Barabasi, A.L.: Network Science. Cambridge University Press, UK (2016)

[3] Bollen, J., Gonçalves, B., van de Leemput, I., Ruan, G.: The happiness paradox: your friends are happier than you. EPJ Data Science 6(1), 4 (2017)

[4] Collaboration, O.S., et al.: Estimating the reproducibility of psychological science. Science 349(6251), aac4716 (2015)

[5] Correa, J.C., Camargo, J.E.: Ideological consumerism in Colombian elections, 2015: Links between political ideology, Twitter activity, and electoral results. Cyberpsychology, Behavior, and Social Networking 20(1), 37-43 (2017) 
[6] Correa, J.C., Garzón, W., Brooker, P., Sakarkar, G., Carranza, S.A., Yunado, L., Rincón, A.: Evaluation of collaborative consumption of food delivery services through web mining techniques. Journal of Retailing and Consumer Services 46, 45-50 (2019)

[7] Correa, T., Hinsley, A.W., De Zuniga, H.G.: Who interacts on the web?: The intersection of users' personality and social media use. Computers in Human Behavior 26(2), 247-253 (2010)

[8] Costa, L.d.F., Oliveira Jr, O.N., Travieso, G., Rodrigues, F.A., Villas Boas, P.R., Antiqueira, L., Viana, M.P., Correa Rocha, L.E.: Analyzing and modeling real-world phenomena with complex networks: a survey of applications. Advances in Physics 60(3), 329-412 (2011)

[9] Gaggioli, A.: CyberSightings. Cyberpsychology, Behavior, and Social Networking 14(10), 625-626 (2011)

[10] Gaggioli, A.: CyberSightings. Cyberpsychology, Behavior, and Social Networking 15(11), 639-640 (2012)

[11] Gaggioli, A.: CyberSightings. Cyberpsychology, Behavior, and Social Networking 16(9), 714 (2013)

[12] Gaggioli, A.: CyberSightings. Cyberpsychology, Behavior, and Social Networking $\mathbf{1 7}(7), 496$ (2014)

[13] Gaggioli, A.: CyberSightings. Cyberpsychology, Behavior, and Social Networking 18(7), $426(2015)$

[14] Gaggioli, A.: CyberSightings. Cyberpsychology, Behavior, and Social Networking 19(12), 746 (2016)

[15] Harley, D., Morgan, J., Frith, H.: Cyberpsychology as Everyday Digital Experience across the Lifespan. Palgrave Macmillan, London (2018)

[16] Holden, M.K.: Virtual environments for motor rehabilitation. Cyberpsychology \& behavior 8(3), 187-211 (2005)

[17] Jaffe, K.: What is science?: An interdisciplinary perspective. University Press of America Lanham, New York (2009)

[18] Kim, C., Mirusmonov, M., Lee, I.: An empirical examination of factors influencing the intention to use mobile payment. Computers in Human Behavior 26(3), 310-322 (2010)

[19] Kolaczyk, E.D., Csárdi, G.: Statistical analysis of network data with R, vol. 65. Springer, New York (2014)

[20] Krombholz, K., Merkl, D., Weippl, E.: Fake identities in social media: A case study on the sustainability of the Facebook business model. Journal of Service Science Research 4(2), 175-212 (2012)

[21] Landers, R.N., Brusso, R.C., Cavanaugh, K.J., Collmus, A.B.: A primer on theory-driven web scraping: Automatic extraction of big data from the internet for use in psychological research. Psychological Methods 21(4), 475 (2016) 
[22] Lazer, D.M., Baum, M.A., Benkler, Y., Berinsky, A.J., Greenhill, K.M., Menczer, F., Metzger, M.J., Nyhan, B., Pennycook, G., Rothschild, D., et al.: The science of fake news. Science 359(6380), 1094-1096 (2018)

[23] Li, Y.M., Yeh, Y.S.: Increasing trust in mobile commerce through design aesthetics. Computers in Human Behavior 26(4), 673-684 (2010)

[24] Lin, K.Y., Lu, H.P.: Why people use social networking sites: An empirical study integrating network externalities and motivation theory. Computers in human behavior 27(3), 1152-1161 (2011)

[25] Mazieres, A., Trachman, M., Cointet, J.P., Coulmont, B., Prieur, C.: Deep tags: toward a quantitative analysis of online pornography. Porn Studies 1(1-2), 80-95 (2014)

[26] Norman, K.L.: Cyberpsychology: An introduction to human-computer interaction. Cambridge university press, UK (2017)

[27] Olson, G.M., Olson, J.S.: Distance matters. Human-computer interaction 15(2-3), 139-178 (2000)

[28] O'Reilly, T.: What is web 2.0: Design patterns and business models for the next generation of software. Communications \& Strategies (1), 17-37 (2007)

[29] Pappalardo, G., Di Matteo, T., Caldarelli, G., Aste, T.: Blockchain inefficiency in the bitcoin peers network. EPJ Data Science 7(1), 30 (2018)

[30] Park, N., Kee, K.F., Valenzuela, S.: Being immersed in social networking environment: Facebook groups, uses and gratifications, and social outcomes. CyberPsychology \& Behavior 12(6), 729-733 (2009)

[31] Piazza, J., Bering, J.M.: Evolutionary cyber-psychology: Applying an evolutionary framework to internet behavior. Computers in Human Behavior 25(6), 1258-1269 (2009)

[32] Pickering, C., Byrne, J.: The benefits of publishing systematic quantitative literature reviews for phd candidates and other early-career researchers. Higher Education Research \& Development 33(3), 534-548 (2014)

[33] R Core Team: R: A Language and Environment for Statistical Computing. R Foundation for Statistical Computing, Vienna, Austria (2018), https: //www.R-project.org/

[34] Raacke, J., Bonds-Raacke, J.: Myspace and facebook: Applying the uses and gratifications theory to exploring friend-networking sites. Cyberpsychology \& behavior 11(2), 169-174 (2008)

[35] Rauzzino, A., Correa, J.C.: Millennials sex differences on snapchat perceived privacy. Suma Psicológica 24(2), 129-134 (2017)

[36] Riva, G.: CyberEurope. Cyberpsychology \& Behavior 9(3), 374-376 (2006)

[37] Riva, G.: CyberEurope. Cyberpsychology \& Behavior 10(2), 321-322 (2007) 
[38] Riva, G.: CyberEurope. Cyberpsychology \& Behavior 11(2), 250-252 (2008)

[39] Riva, G.: CyberEurope. Cyberpsychology and Behavior 12(6), 773 (2009)

[40] Riva, G.: CyberEurope. Cyberpsychology and Behavior 13(6), 719 (2010)

[41] Riva, G.: CyberEurope. Cyberpsychology, Behavior, and Social Networking 14(4), 263 (2011)

[42] Riva, G.: CyberEurope. Cyberpsychology, Behavior, and Social Networking 15(6), 334 (2012)

[43] Riva, G.: CyberEurope. Cyberpsychology, Behavior, and Social Networking 16(10), 780 (2012)

[44] Riva, G.: CyberEurope. Cyberpsychology, Behavior, and Social Networking $\mathbf{1 7}(8), 568$ (2014)

[45] Riva, G.: CyberEurope. Cyberpsychology, Behavior, and Social Networking 18(6), 362 (2015)

[46] Riva, G.: CyberEurope. Cyberpsychology, Behavior, and Social Networking 19(2), 155 (2016)

[47] Russell, M.: Mining the Social Web. O'Reilly Media, California (2014)

[48] Salas, G., Ravelo-Contreras, E.L., Mejía, S., Andrades, R., Acuña, E., Espinoza, F., Núñez, M., Barboza-Palomino, M., Ventura-León, J., CaychoRodríguez, T., et al.: Dos décadas de acta colombiana de psicología: un análisis bibliométrico. Acta Colombiana de Psicología 21(2), 13-38 (2018)

[49] Tess, P.A.: The role of social media in higher education classes (real and virtual)-a literature review. Computers in Human Behavior 29(5), A60A68 (2013)

[50] Tokunaga, R.S.: Following you home from school: A critical review and synthesis of research on cyberbullying victimization. Computers in human behavior 26(3), 277-287 (2010)

[51] Vanderhoven, E., Schellens, T., Valcke, M., Raes, A.: How safe do teenagers behave on facebook? an observational study. PLoS One 9(8), e104036 (2014)

[52] van Wegberg, R., Oerlemans, J.J., van Deventer, O.: Bitcoin money laundering: mixed results? an explorative study on money laundering of cybercrime proceeds using bitcoin. Journal of Financial Crime 25(2), 419-435 (2018)

[53] Wickham, H., Grolemund, G.: R for data science: import, tidy, transform, visualize, and model data. " O'Reilly Media, Inc.", New York (2016)

[54] Wood, M.J.: Propagating and Debunking Conspiracy Theories on Twitter During the 2015-2016 Zika Virus Outbreak. Cyberpsychology, Behavior, and Social Networking 21(8), 485-490 (2018) 
[55] Yee, N.: Motivations for play in online games. CyberPsychology \& Behavior $\mathbf{9}(6), 772-775(2006)$

[56] Young, K.S.: Cognitive behavior therapy with internet addicts: treatment outcomes and implications. CyberPsychology \& Behavior 10(5), 671-679 (2007)

[57] Young, R., Subramanian, R., Miles, S., Hinnant, A., Andsager, J.L.: Social representation of cyberbullying and adolescent suicide: A mixed-method analysis of news stories. Health communication 32(9), 1082-1092 (2017) 